\title{
THE EFFECT OF AGE AND PERSONALITY ON THE MAIN COGNITIVE PROCESSES IN DRIVERS
}

\author{
MARCIN BIERNACKI ${ }^{1}$ and ADAM TARNOWSKI ${ }^{2}$ \\ ${ }^{1}$ Military Institute of Aviation Medicine, Warszawa, Poland \\ ${ }^{2}$ University of Warsaw, Warszawa, Poland \\ Faculty of Psychology
}

\begin{abstract}
Objectives: The purpose of this study is the evaluation of how the decline of cognitive abilities caused by aging is moderated by biologically determined personality dimensions: Neuroticism $(\mathrm{N})$ and Extraversion $(\mathrm{E})$. Materials and Methods: The research was conducted with the participation of $160 \mathrm{men}$ in good physical health, professional drivers, aged 20-70 $($ Mean $=40, S D=11)$. Personality traits were measured using Eysenck's Personality Questionnaire - Revised $(E P Q-R)$, while Ravens Progressive Matrices, Go/noGo Task and Peripheral Perception Test were used to evaluate cognitive processes. The score of Ravens Progressive Matrices was treated as a control variable. Results: The results of the study, based on a Hierarchical Multiple Regression Analysis, indicate that besides the intelligence level, age is the best predictor of cognitive functioning level and that this influence is additionally moderated by the $\mathrm{N}$ trait level as well as, less frequently, by the interaction of age and $\mathrm{E}$. Conclusion: This means that high $\mathrm{N}$ trait level increases the influence of age on cognitive functions decline. When the $\mathrm{N}$ trait level was low, the age differences in measures of cognitive performance were not significant. Thus, the level of $\mathrm{N}$ trait may play an important role in the process of cognitive aging. The results are discussed in the context of a driving safety research.
\end{abstract}

Key words:

Personality, Age, Cognition, Neuroticism, Extraversion

\section{INTRODUCTION}

The search for factors responsible for the condition of particular cognitive functions is the subject of basic as well as applied research. Professional drivers studies, such as fitto-drive assessment [1], form an example of the latter. The advancement in medicine and the increase in one's functioning standards constitute some of the factors influencing the increase of human lifespan. Despite the fact that societies are aging, as frequently demonstrated, age itself does not prevent being active on many different levels of social life [2]. Older people want to continue to be active and they find it hard to give up tasks which constitute their daily living. Driving a car is one such activity [3,4]. Research indicates that giving up active driving may result in a decline of the quality of life [3] or contribute to the likelihood of depression symptoms' occurrence in older people [4]. It is important to note however, that driving, as opposed to all other daily activities, is linked to the risk of death of the driver or other traffic participants [5,6]. Therefore, the definition of factors correlating with the decline of cognitive processing or undertaking risqué behaviors gains particular importance when examining older drivers.

The research exploring particular aspects of older drivers' cognitive functioning most frequently focuses on

The research was supported by a grant PL0088 from Iceland, Liechtenstein and Norway through the EEA Financial Mechanism and the Norwegian Financial Mechanism Received: May 30, 2011. Accepted: June 22, 2011.

Address reprint request to M. Biernacki, Military Institute of Aviation Medicine, Krasińskiego 54, 01-755 Warszawa, Poland (e-mail: mpbiernacki@gmail.com). 
determining the role of age or specific personality traits. While the influence of age on cognitive processing is an increasingly better-known area of research, the effect of age and personality traits on the functioning of older drivers approached from an interactive perspective is rarely reported.

\section{Age- and driving-related cognitive factors}

The question whether age contributes to the driving ability decline and the incident frequency increase has been the subject of numerous research projects. Whereas it has been established that aging correlates with a decline of a cognitive functions level [7], the occurrence of car accidents is not only driven by the cognitive functions, but also personality traits and the level of experience [8]. Williams [9] demonstrated that on a per-mile basis, the nonfatal accident rate for 16-year-old novices is more than 10 times that of adults and almost three times that of 18-year olds. According to McKnight \& McKnight [8], such results can be explained by the fact that younger persons are more prone to errors in attention, visual search, speed relative to conditions, hazard recognition, and emergency maneuvers which may be the effect of the lack of experience. Additionally, the research conducted by Ryan, Legge \& Rosman [10] brings to attention the fact that when analyzing traffic accidents it is important to consider the distance traveled. When the distance traveled was taken into consideration in their study, they illustrated that the rates of crash involvement for the 75 or more age group were as high as those of the youngest age group [10]. The same results were found in the study of Evans [11]. Porter \& Whitton [12] showed in their laboratory research that while older drivers drove more carefully in comparison to younger drivers, they also had more difficulty with turning, signaling, and exhibited inattention. On the other hand, Wood [13] proved that older persons had worse results in vision testing (motion sensitivity, UFOV, Pelli-Robson letter contrast sensitivity, and dynamic acuity), which appears to be congruent with Porter \& Whitton's [12] research results. It is important to emphasize that in Wood's research [13], visual functions explained as much as 50\% of the variance in overall driving scores. According to Wood [13], these results indicate that older drivers with either normal vision or visual impairment had poorer driving performance compared with younger or middle-aged drivers with normal vision.

The results of research exploring the correlation between age and response time unanimously indicate that as one ages, the response time becomes extended, which according to Birren \& Fisher [14] is one of the better documented associations [15]. This relation applies more suitably to tasks testing the complex response time, as opposed to the simple response time, and it increases along with the increase in the number of possible choices [16]. These results can be explained by the fact that older persons' nervous system operates slower and is less efficient in transmitting signals, and the difficulties caused by additional choices are the manifestations of the function of age and complexity effect [17].

Similarly to response time, the level of visual-motor coordination decreases as one is aging, which has been proven by Guan \& Wade's [18] research results. They speculate that this decline may be caused by the age-related change in strategic control and, to some extent, a decrease in spatial alignment. Another key factor in driving a vehicle, which apparently is related to age, is the speed assessment. Research indicates that the speed assessment ability decreases with age [19,20]. For instance, Staplin, Lococo, and Sim [21] found that the perceptual basis of "time-tocollision" and "traffic gap acceptance judgments" changes significantly with age. Older drivers tended to underestimate the time required for an approaching vehicle to reach their current position.

All these results strongly indicate that older drivers have less effective bottom-up, whereas younger drivers have less effective top-down processes. 


\section{Personality- and driving-related cognitive factors}

When introducing personality variables to our study, we had to decide which personality traits have crucial importance and which tools to use to measure them. The examination of the personality traits role in drivers' behavior has been based on traits constituting the PEN model, "The Big Five", as well as other personality dimensions, such as sensationseeking. In our study, we wanted to verify the assumption that the influence of age on cognitive processing is regulated by the level of specific personality traits. Therefore, we decided that it would be most appropriate to refer to a personality theory, which strongly emphasizes its biological foundation [22]. Basing our research on one of the biological personality theories, which refers personality to the nervous system's qualities, potentially gives us the possibility of tying the research results to well-documented influence of aging on the cognitive processing decline (e.g., attention flexibility or processing speed), which is explained by changes in the nervous system. Amongst many personality traits we chose to base our research on Eysenck's P-E-N model [23]. Based on this theor,y Eysenck formulated a hypothesis that the intensity of $E$ trait reflects the variability of energetic activity of cortical arousal on the physiological level, while the intensity of $\mathrm{N}$ trait reflects the function of anxiety-causing stimulation of the limbic system [23]. According to this theory, extroverts are characterized by higher levels of activity than introverts, and people who score highly on measures of neuroticism have a more reactive sympathetic nervous system comparing to those who score lower. However, no hypotheses or data have been reported by Eysenck which allow for any conclusion regarding the physiological basis of psychoticism and its relationship with performance.

On a theoretical level, Eysenck hypothesized that drivers who are characterized by high levels of $\mathrm{N}$ and $\mathrm{E}$ traits are more likely to have accidents. However, the results of empirical research are not as unanimous and often deliver conflicting data. For instance, the results of Renner \& Anderle's [24] or Lajunen's [25] research demonstrated a positive relationship between extraversion and accident involvement, while in other experiments such correlation was not found [26], or an opposite correlation was discovered [27]. Clarke \& Robertson [28] proved, in one of the most recent meta-analyses, that all in all, the E trait level is related to traffic accidents. These researchers argue that extraverts are particularly prone to accidents when performing a task in monotonous conditions requiring sustained attention [28]. Similarly, the results of studies investigating the correlation between the $\mathrm{N}$ trait levels and proneness to accidents are non-unanimous. Some studies applying both the correlation techniques [29] and a criterion group design [30] indicate lack of such connection. Newer studies show that such correlation exists [28] proving that $\mathrm{N}$ trait is associated with accident risk and aberrant driving behaviors. Clarke \& Robertson [28] attribute this connection to the fact that $\mathrm{N}$ trait is strongly linked to stress caused by accident involvement [31,32].

In conclusion, the influence of age and personality traits on the driver's cognitive processing has been under discussion for a significant period of time. However, we lack data that refers simultaneously to both these dimensions in relation to cognitive functioning, especially in drivers. The purpose of our study was to examine how the basic personality traits, $\mathrm{N}$ and $\mathrm{E}$, and the drivers' age affect their cognitive processing. We based such research objective on the fact that changes in basic cognitive dimensions caused by aging are explained by changes in the nervous system, which in turn allows us to hypothesize that there is a correlation between these changes and the level of biologically determined personality traits $\mathrm{N}$ and $\mathrm{E}$.

\section{METHODS}

\section{Participants and measures}

160 healthy men participated in the study, all of whom were active professional drivers aged 20-70 $(\mathrm{M}=40$, $\mathrm{SD}=11$ ). Prior to the study, all of the selected drivers 
were medically examined, by an ophthalmologist and a neurologist, and certified to be fit to drive by a licensed physician. The study was conducted in laboratory conditions. The personality traits were measured with the use of the Polish adaptation [33] of Eysenck's Personality Questionnaire-Revised (EPQ-R). We decided to choose EPQ-R because it has a strong biological-constitutional basis. The analysis encompassed measures $\mathrm{N}$ and $\mathrm{E}$, as well as age, while the dependent variables were the basic dimensions of cognitive processing, which we established as the quickness and lability of the response time and the cooperation of peripheral and central processes of attention.

Obviously, the question which cognitive functioning aspects should be recognized as key factors in driving [34] could make the topic of a separate article. Quickness, variability and precision of response are identified amongst many other factors as key aspects of cognitive processing [1]. Additional crucial factors are speed estimation related to high angular velocity in the peripheral visual field, steering a car associated with eye-hand coordination and observance of the surroundings, which is the result of information integration in the central and peripheral field of vision $[19,18]$.

The quickness and lability of the response time were measured using Reaction Time (RT) in the Go/noGo Task paradigm [35]. This test was performed in the Schuhfried apparatus [36]. The subjects' task was to respond, by pressing a button, only to a meaningful stimulus, which consisted of concurrent yellow light and sound, and to omit other combinations of stimuli (yellow light; red light; sound; red light and sound; red and yellow light and sound). The following variables were evaluated:

- median latency time - the time between stimulus presentation and releasing the rest button;

- median motor time - the time between releasing the rest button and pressing the reaction button after a stimulus has been presented;
- interquartile range (variability) of latency time - the indicator of intraindividual variation of latency time;

- interquartile range (variability) of motor time - the indicator of intraindividual variation of motor time.

The total reaction time (and its variability) was not analyzed in the study because it consists of the sum of latency and motor time. Thus, such analysis would not provide any significant information.

The second test utilized in this study was Peripheral Perception (PP) Test, also designed by Schuhfried [37]. The test consists of two concurrent sub-tasks: one requires a response to stimuli appearing in the peripheral field of vision, the other involves coordinating a centrally located element. Thus, PP accounts for switching and dividing attention. The main measured variables are as follows:

Field of Vision represents the entire field of vision in degrees, which results from the sum of the left and right visual angles. A visual angle is calculated based on a grid position, position of the cross-hairs and the distance of the head from the measuring unit;

- tracking deviation — deviation of the cross-hairs from the central target;

- omitted reactions - no reaction to a required peripheral stimulus;

1. The performance of both Go/noGo Task and PP tests was preceded by an instructional phase.

2. Last but not least, all participants were given Raven's Standard Progressive Matrices (SPM) [38]. This test measures the reasoning ability, general intelligence and Spearman's g [39]. The SPM test consists of 60 diagrammatic puzzles, each with a missing part which the test taker attempts to identify from several options. In our study, the score of SPM was treated as a control variable.

\section{Statistical analysis}

A Hierarchical Multiple Regression Analysis was performed in order to predict cognitive processes based on 
the $\mathrm{N}$ and $\mathrm{E}$ trait levels, age, and the interaction of these variables [40]. Several regression models were built to accomplish this goal. In the first step, the level of SPM was introduced as a control variable. In the second step, the predictors consisted of age and the level of $\mathrm{N}$ and $\mathrm{E}$ traits. In the third and fourth step, 2-way interactions between personality traits and age were introduced to the equation. In the fifth one, a model $\mathrm{N}$ and $\mathrm{E}$ interaction was introduced. In the last step, we included a 3-way interaction in an Age $\times \mathrm{N} \times \mathrm{E}$ form [40]. In regression models constructed in such a way, the age was the main independent variable, whereas the levels of $\mathrm{N}$ and $\mathrm{E}$ traits were treated as moderators [40]. In addition to this, intelligence $(\mathrm{g})$ age and personality were treated as continuous variables and standardized before calculation [41].

\section{RESULTS}

We began with the analysis of variables comprising Reaction Time (RT) in the Go/noGo Task paradigm: motor time and latency time, as well as their interquartile range (Table 1). Among the independent variables, age appears to be the best predictor of motor time, $\beta=0.273 p<0.01$. This result indicates that the older the person, the longer it takes them to move from the rest field to the response field. The other variables, $\mathrm{N}$ and $\mathrm{E}$, and their interaction did not seem to have any valid influence on motor time. Similarly, age appears to be the best predictor of latency time, $\beta=0.331 \mathrm{p}<0.001$. This influence is demonstrated by the fact that the older the person, the longer the stimuli processing time and the time taken to choose the correct answer: moving or not moving the arm from the rest field to the response field. Our results also show

Table 1. Summary of Hierarchical Multiple Regression Analysis for intelligence, age and Eysencks PEN predicting Go/noGo Task variables

\begin{tabular}{|c|c|c|c|c|c|c|c|c|c|c|c|c|}
\hline \multirow{3}{*}{ Predictor } & \multicolumn{12}{|c|}{ Go/noGo Task variables } \\
\hline & \multicolumn{3}{|c|}{ latency time } & \multicolumn{3}{|c|}{ motor time } & \multicolumn{3}{|c|}{$\begin{array}{c}\text { interquartile range } \\
\text { of latency time }\end{array}$} & \multicolumn{3}{|c|}{$\begin{array}{l}\text { interquartile range } \\
\text { of motor time }\end{array}$} \\
\hline & $\Delta \mathrm{R}^{2}$ & Adj. $R^{2}$ & $\beta$ & $\Delta \mathrm{R}^{2}$ & Adj.R ${ }^{2}$ & $\beta$ & $\Delta \mathrm{R}^{2}$ & Adj.R ${ }^{2}$ & $\beta$ & $\Delta \mathrm{R}^{2}$ & Adj.R ${ }^{2}$ & $\beta$ \\
\hline Step 1 & 0.006 & 0.001 & & 0.001 & 0.006 & & $0.067^{* *}$ & $0.060^{* *}$ & & 0.005 & 0.002 & \\
\hline \multicolumn{13}{|l|}{ SPM } \\
\hline Step 2 & $0.111^{* * *}$ & * $0.091^{* * *}$ & & $0.089^{*}$ & $0.056^{*}$ & & $0.086^{* *}$ & $0.123^{* *}$ & & $0.208^{* * *}$ & $0.183^{* * *}$ & \\
\hline Age & & & $0.331^{* * *}$ & & & $0.273^{*}$ & & & $0.253^{* *}$ & & & $0.328^{* *}$ \\
\hline $\mathrm{N}$ & & & 0.046 & & & -0.066 & & & 0.082 & & & $0.161^{*}$ \\
\hline $\mathrm{E}$ & & & 0.004 & & & -0.098 & & & -0.025 & & & $-0.165^{*}$ \\
\hline Step 3 & $0.029^{*}$ & $0.114^{*}$ & & 0.003 & 0.052 & & $0.046^{* *}$ & $0.164^{* *}$ & & $0.041^{* *}$ & 0.220 & \\
\hline Age $\times N$ & & & $0.176^{*}$ & & & 0.052 & & & $0.220^{* *}$ & & & $0.206^{* *}$ \\
\hline Step 4 & 0.000 & 0.101 & & 0.004 & 0.050 & & 0.000 & 0.156 & & $0.022^{*}$ & $0.237^{*}$ & 0.000 \\
\hline Age $\times \mathrm{E}$ & & & 0.012 & & & -0.069 & & & 0.016 & & & $-0.161^{*}$ \\
\hline Step 5 & 0.000 & 0.088 & & 0.006 & 0.042 & & 0.011 & 0.154 & & 0.016 & 0.245 & \\
\hline$N \times E$ & & & 0.001 & & & 0.079 & & & 0.112 & & & -0.134 \\
\hline Step 6 & 0.006 & 0.088 & & 0.003 & 0.037 & & 0.005 & 0.153 & & 0.008 & 0.248 & \\
\hline Age $\times \mathrm{N} \times \mathrm{E}$ & & & 0.090 & & & 0.059 & & & -0.079 & & & -0.104 \\
\hline
\end{tabular}

$* \mathrm{p}<0.05,{ }^{* *} \mathrm{p}<0.01,{ }^{* * *} \mathrm{p}<0.001$ 


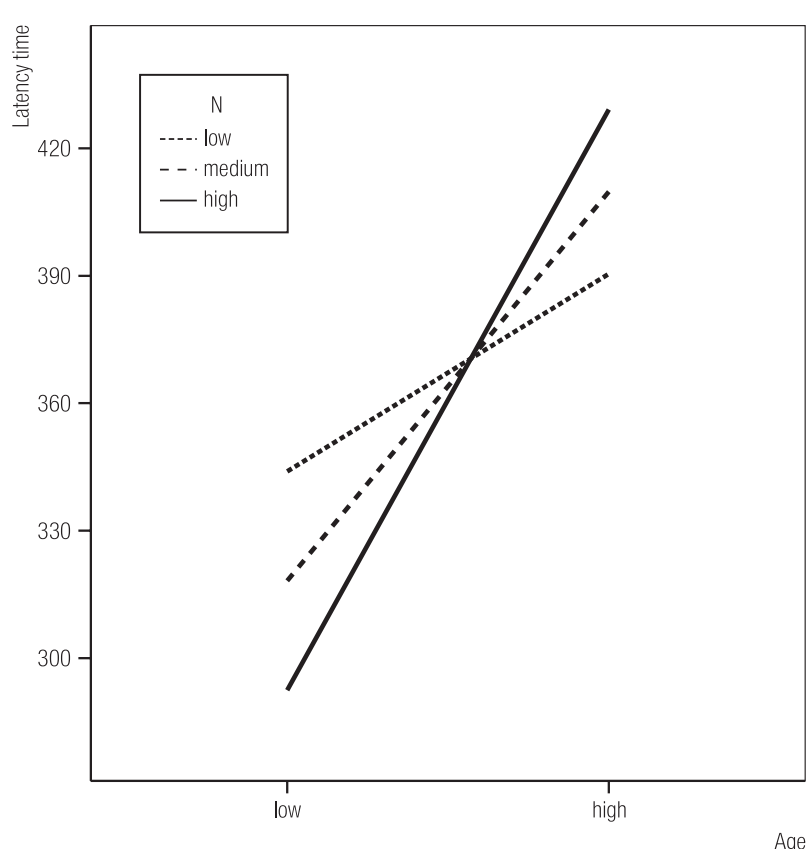

Fig. 1. The influence of age on latency time depending on the level of $\mathrm{N}$ trait.

that this influence is additionally moderated by the level of $\mathrm{N}$ trait, $\beta=0.176, \mathrm{p}<0.05, \mathrm{~F}(1,157)=4.3, \mathrm{p}<0.05$. This interaction is illustrated on the chart (Figure 1).

The influence of age and the $\mathrm{N}$ trait level is of additive nature. As demonstrated on the chart above, latency time is significantly higher in older people characterized by high scores on the $\mathrm{N}$ measure. This means that the higher the $\mathrm{N}$ level, the stronger the age influence on latency time (synergy effect).

In addition to variables constituting quickness of response (analyzed above), a person's ability to maintain an even tempo is of great importance. Amongst the studied independent variables, age appears to be the best predictor of interquartile range of motor time, $\beta=0.328, p<0.001$. The older the person, the larger the interquartile range of motor time. Additionally, the interaction between Age $\times \mathrm{E}$ and Age and $\mathrm{N}$ variables also proved to be valid. For age and $\mathrm{E}: \beta=-0.161, \mathrm{~F}(1,157)=6.8, \mathrm{p}<0.01$. And for Age and $\mathrm{N}: \beta=0.206, \mathrm{~F}(1,157)=4.2, \mathrm{p}<0.05$. This interaction is illustrated on the chart (Figure 2).
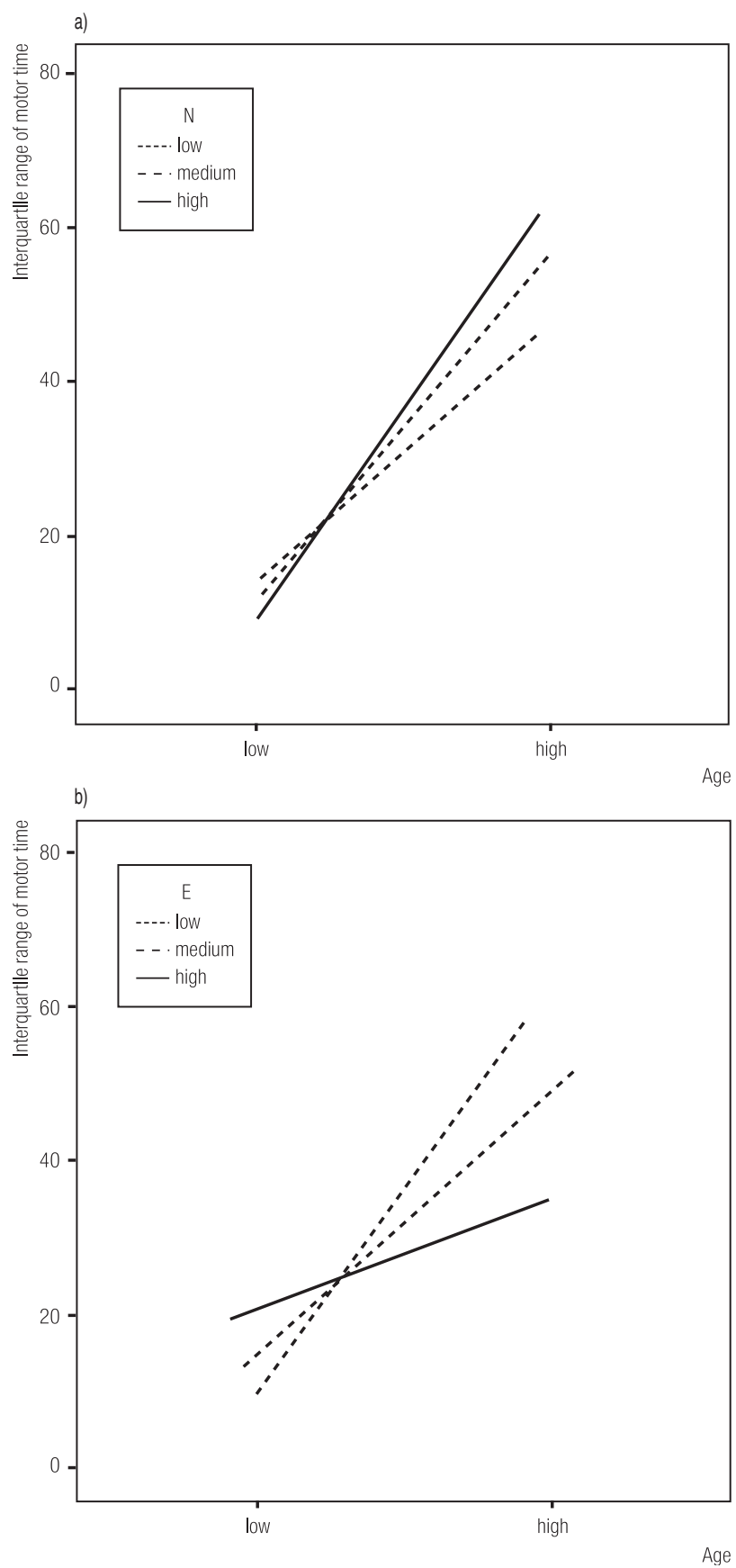

Fig. 2. The influence of age on the interquartile range of motor time depending on the level of $\mathrm{N}(\mathrm{a})$ and $\mathrm{E}$ trait (b).

As demonstrated on the previous chart, the influence of age on the interquartile range of motor time is valid in persons characterized by low scores on the E measure and, independently, for those characterized by high scores on $\mathrm{N}$ trait. Older persons characterized by high scores 


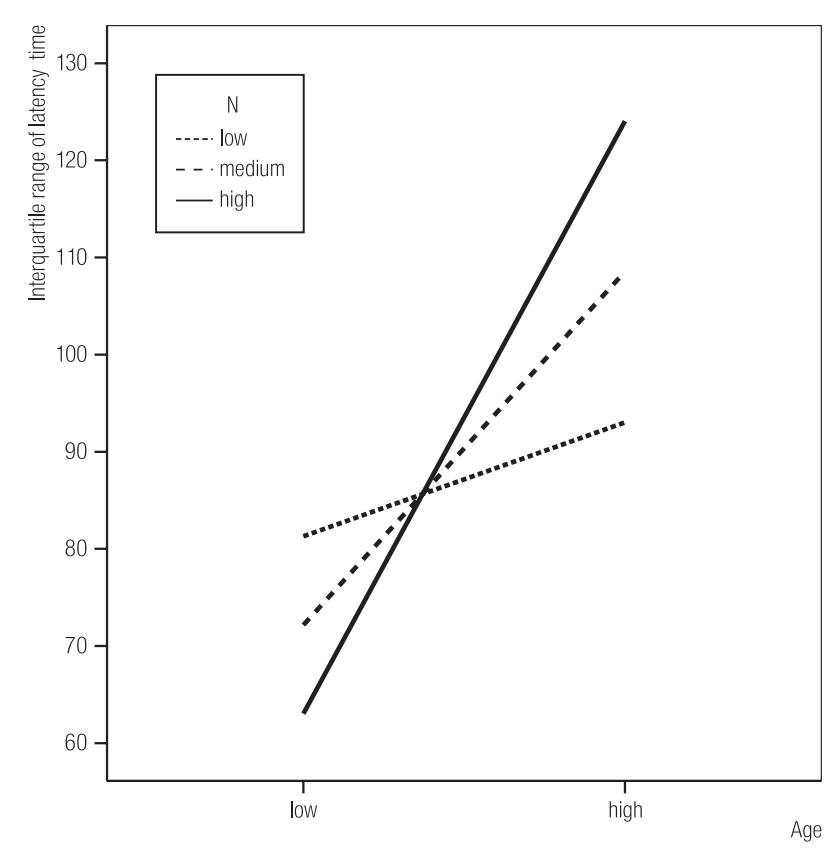

Fig. 3. The influence of age on the interquartile range of latency time depending on the level of $\mathrm{N}$ trait.

on the $\mathrm{N}$ measure exhibit significantly larger interquartile range of motor time. On the contrary, older persons characterized by low scores on the E measure exhibit significantly smaller interquartile range of motor time. The lower the level of $\mathrm{E}$ trait, or the higher the $\mathrm{N}$ level, the stronger the influence exerted by age on interquartile range of motor time. Similarly, age seems to be the best predictor of interquartile range of latency time, $\beta=0.253, p<0.005$. The older the persons, the larger the interquartile range of latency time. Additionally, age interacts with the level of $\mathrm{N}$ trait, $\beta=0.220, p<0.01 ; F(1,157)=4.367, p<0.05$. This interaction is illustrated on the chart below (Figure 3 ).

As demonstrated on the above chart, the influence of age and the $\mathrm{N}$ trait level on the interquartile range of latency time is of additive nature. The interquartile range of latency time is significantly larger in persons who are older and are characterized by high score on the $\mathrm{N}$ measure, as opposed to persons who are younger and score highly on the $\mathrm{N}$ measure. The higher the level of $\mathrm{N}$ trait, the stronger the influence age has on the interquartile range of latency time (synergy effect).

Next, we analyzed the indicators constituting the Peripheral Perception Test: Field of Vision, tracking deviation, and omitted reactions (Table 2).

Table 2. Summary of Hierarchical Multiple Regression Analysis for intelligence, age and Eysencks PEN predicting PP variables

\begin{tabular}{|c|c|c|c|c|c|c|c|c|c|}
\hline \multirow{3}{*}{ Predictor } & \multicolumn{9}{|c|}{ PP variables } \\
\hline & \multicolumn{3}{|c|}{ field of vision } & \multicolumn{3}{|c|}{ tracking deviation } & \multicolumn{3}{|c|}{ omitted reactions } \\
\hline & $\Delta \mathrm{R}^{2}$ & Adj. $R^{2}$ & $\beta$ & $\Delta \mathrm{R}^{2}$ & Adj.R ${ }^{2}$ & $\beta$ & $\Delta \mathrm{R}^{2}$ & Adj.R ${ }^{2}$ & $\beta$ \\
\hline $\begin{array}{l}\text { Step } 1 \\
\text { SPM }\end{array}$ & $0.089^{* * * *}$ & $0.081^{* *}$ & & $0.039^{*}$ & $0.030^{*}$ & & $0.034^{*}$ & $0.025^{*}$ & \\
\hline Step 2 & $0.138^{* * *}$ & $0.190^{* * *}$ & & $0.104 *$ & $0.102 * *$ & & $0.083^{*}$ & $0.076^{*}$ & \\
\hline Age & & & $-0.394^{* * *}$ & & & $0.307^{* * *}$ & & & $0.280^{* *}$ \\
\hline $\mathrm{N}$ & & & 0.099 & & & 0.066 & & & 0.072 \\
\hline $\mathrm{E}$ & & & -0.058 & & & -0.058 & & & -0.007 \\
\hline Step 3 & $0.026^{*}$ & $0.210^{*}$ & & $0.054^{* *}$ & $0.151^{*}$ & & $0.027^{*}$ & $0.095^{*}$ & \\
\hline Age $\times \mathrm{N}$ & & & $-0.169^{*}$ & & & $0.244^{* *}$ & & & $0.169^{*}$ \\
\hline Step 4 & 0.000 & 0.203 & & 0.008 & 0.152 & & 0.007 & 0.094 & \\
\hline Age $\times E$ & & & 0.016 & & & -0.094 & & & -0.086 \\
\hline Step 5 & 0.012 & 0.201 & & 0.010 & 0.160 & & 0.000 & 0.082 & \\
\hline $\mathrm{N} \times \mathrm{E}$ & & & -0.119 & & & 0.107 & & & 0.015 \\
\hline Step 6 & 0.004 & 0.197 & & 0.006 & 0.158 & & 0.001 & 0.074 & \\
\hline Age $\times \mathrm{N} \times \mathrm{E}$ & & & -0.078 & & & -0.098 & & & -0.034 \\
\hline
\end{tabular}

$* \mathrm{p}<0.05,{ }^{*} \mathrm{p}<0.01,{ }^{* * *} \mathrm{p}<0.0010$ 


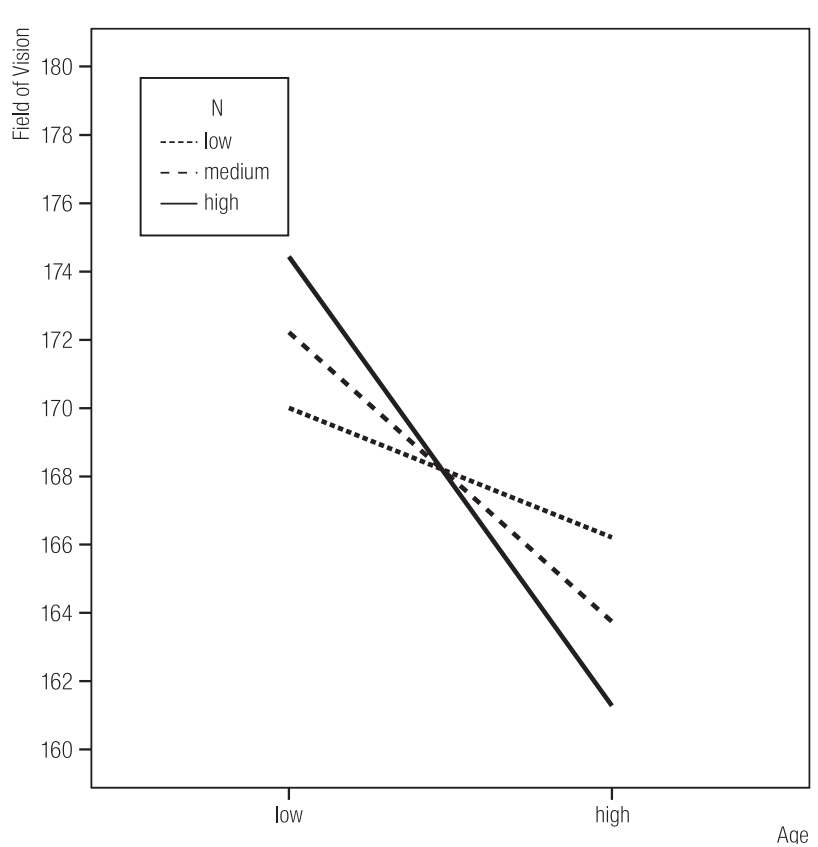

Fig. 4. The influence of age on the Field of Vision depending on the level of $\mathrm{N}$ trait.

Among the studied variables, age proves to be the best predictor of the Field of Vision in the study participants, $\beta=-0.394, p<0.001$. The older the person, the smaller the Field of Vision. Moreover, age interacts with the level of $\mathrm{N}$ trait, $\beta=-0.169, \mathrm{p}<0.05, \mathrm{~F}(1,157)=5.665, \mathrm{p}<0.05$. This interaction is illustrated on the chart (Figure 4).

As presented on the chart above, the Field of Vision is significantly smaller in persons who are older and characterized by high scores on the $\mathrm{N}$ measure, contrary to persons who are younger and score highly on the $\mathrm{N}$ measure. The higher the level of $\mathrm{N}$ trait, the stronger the influence age has on the Field of Vision (synergy effect).

Subsequently, we analyzed tracking deviation and found that its level is also most dependant on age, $\beta=0.307$, $p<0.001$. This means that tracking deviation is higher in older persons. Apart from that, age interacts with the level of $\mathrm{N}$ trait, $\beta=0.244, \mathrm{p}<0.01, \mathrm{~F}(1,157)=3.850, \mathrm{p}<0.05$. This interaction is illustrated on the chart (Figure 5). As shown on the chart above, tracking deviation is significantly higher in persons who are older and are

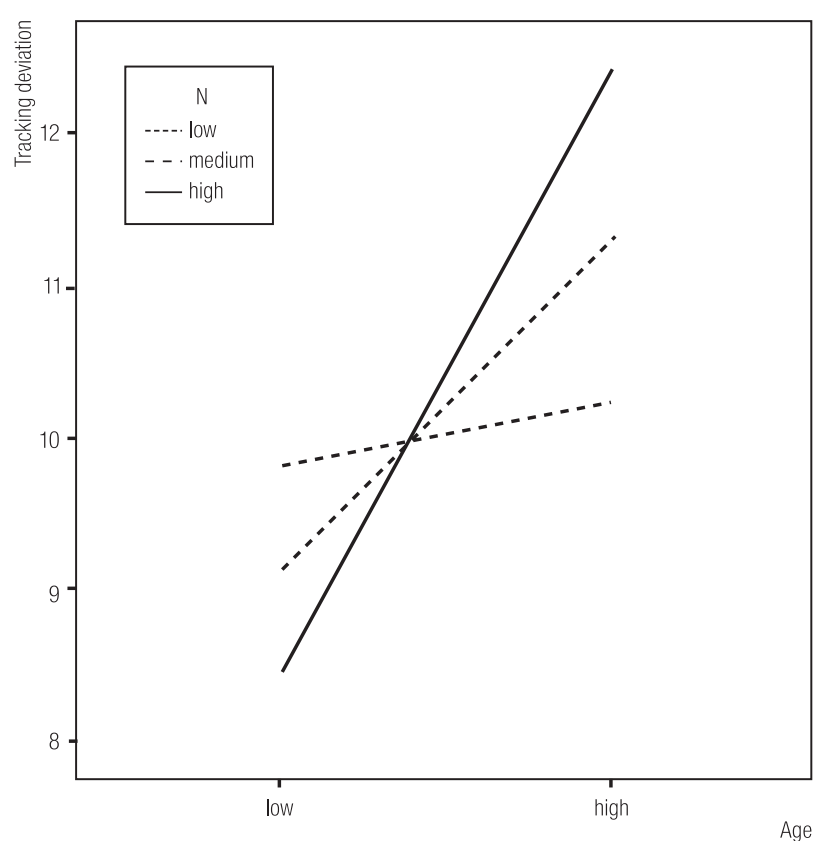

Fig. 5. The influence of age on tracking deviation depending on the level of $\mathrm{N}$ trait.

characterized by high scores on the $\mathrm{N}$ measure, as opposed to persons who are younger and score highly on the $\mathrm{N}$ measure. The higher the level of $\mathrm{N}$ trait, the

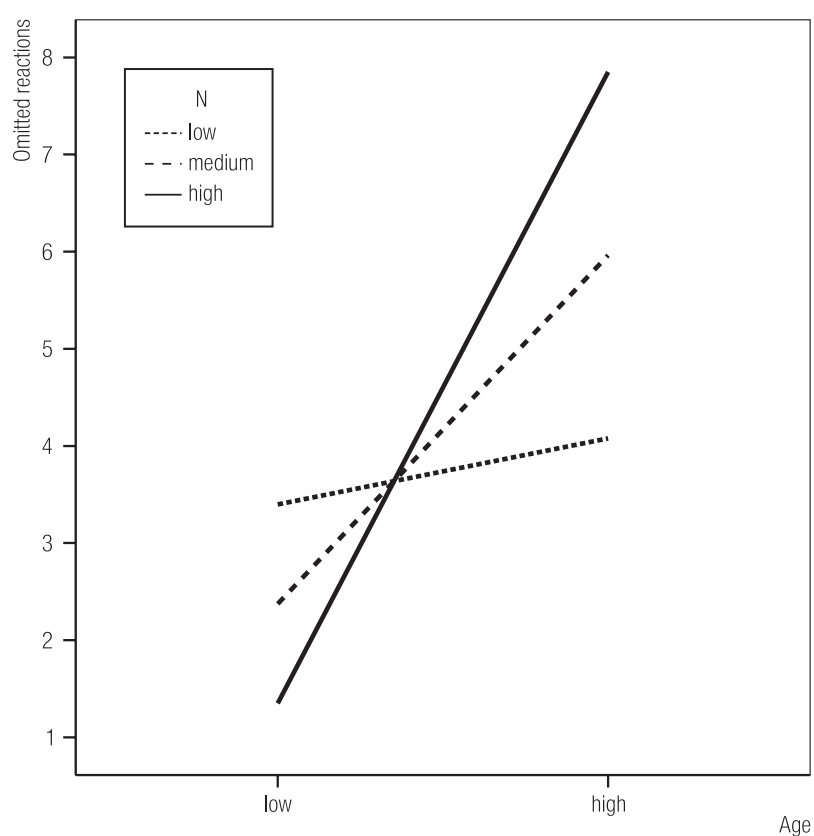

Fig. 6. The influence of age on omitted reactions depending on the level of $\mathrm{N}$ trait. 
stronger the influence age has on tracking deviation (synergy effect).

Age appears to be the best predictor of the number of omitted reactions, $\beta=0.280, p<0.05$. The older the persons, the higher the number of omitted reactions. Additionally, age interacts with the $\mathrm{N}$ trait level, $\beta=0.169$, $\mathrm{p}<0.01, \mathrm{~F}(1,157)=4.749, \mathrm{p}<0.05$. This interaction is illustrated on the chart (Figure 6).

As demonstrated on the chart above, the number of omitted reactions is significantly higher in persons who are older and characterized by high scores on the $\mathrm{N}$ measure, contrary to persons who are younger and score highly on the $\mathrm{N}$ measure. The higher the level of $\mathrm{N}$ trait, the stronger the influence age has on the number of omitted reactions (synergy effect).

\section{DISCUSSION}

The results of our study are congruent with the data found in literature and confirm that age is the deciding factor for cognitive processing, which is of crucial importance in operating a vehicle. Additionally, we demonstrated that the influence of age on cognitive processing is moderated by the level of biologically determined personality traits. What is interesting is that such a result was obtained when controlling the $\mathrm{g}$ level. It is particularly important in the case of many studies which emphasized the relationship between processing speed, attention and g, and the decline of $g$ with ageing $[39,42]$. Among the three personality traits considered by us, the level of $\mathrm{N}$ trait most frequently interacted with age. In case of the majority of variables reflecting cognitive processing in our study the influence of age appears to be higher when the scores on the N measure are higher as well. This correlation was achieved with median latency time, interquartile range of motor and latency time, field of vision, tracking deviation and omitted reactions. In one case, the influence of age was moderated by the level of $E$ trait. This effect was observed for interquartile range of motor time. In accordance with that, when the $\mathrm{N}$ trait level is low, the age differences in the measures of cognitive performance were not significant. This means that age-related differences in the measures of cognitive speed and divided attention cannot be simply put down to the differences in the intellectual functioning between the young and the old $[39,43]$.

While the obtained results demonstrating the influence of age on the level of cognitive processing are not surprising and are explained by the aging of the nervous system, the fact that this influence is moderated by the level of personality test is not as obvious [44]. In the realm of variables constituting the RT in Go/noGo Task it is important to notice that amongst the considered predictors, age proved to be the best predictor of motor time, while in the case of latency time, this influence was additionally moderated by the level of $\mathrm{N}$ trait. Whereas motor time may be treated as an indicator of the muscular systems efficiency, latency time is an indicator of the quickness of the nervous system, and in the case of Go/noGo Task it is also an indicator of the information processing speed, a measure of executive control processes, particularly inhibition [17]. It is important to mention that the level of $\mathrm{N}$ trait moderated the influence of age in these aspects of RT which are controlled by information processing, but not muscular system efficiency (motor time). On the other hand, the variability of the RT subscales describes the ability to maintain the constant quality of performance. The influence of age on variables indicating the lability of reaction was additionally moderated by the level of $\mathrm{N}$ trait as well as E trait, which was described above. Similar study results were obtained by Robinson \& Tamir [45], although their results referred to the immediate correlation between the level of $\mathrm{N}$ trait and the reaction time variability excluding the influence of age.

While RT in the Go/noGo Task paradigm utilizes stimuli presented only in the central field of vision, PP requires simultaneous coordination of stimuli appearing in both 
central and peripheral fields of vision. Age proved to be the best predictor of the Field of Vision, tracking deviation and omitted reactions, although similarly to the previously described variables, its influence was moderated by the level of $\mathrm{N}$ trait. Hence, when it comes to the size of the field of vision and the level of coordination in the central and peripheral field of vision information processing, age is the best predictor, while the level of $\mathrm{N}$ trait is a moderator.

Peripheral vision plays a crucial role not only in observing one's surroundings, important in e.g., changing lanes, but also in the assessment of speed. Rods, whose qualities deteriorate with age, control peripheral vision. Therefore, the fact that the field of vision decreases and the number of omitted reactions increases as one ages is understandable. Correspondingly, the decrease in the tracking deviation level, which is a measure of visual-motor coordination, relates to the results of the previous studies. However, the moderating influence of $\mathrm{N}$ trait has not been directly addressed by the previous research. The connection between older persons' cognitive processing and their personality traits has obviously been studied in the past, yet personality traits were not treated in that research as the obvious moderators [44].

Eysenck hypothesized that neuroticism, as a tendency to express negative emotional states, such as anxiety and emotional tension, would mediate performance and behavior in situations that increase the activity of the visceral brain (under high activation). Hence, high $\mathrm{N}$ scorers are more likely than low $\mathrm{N}$ scorers to become autonomically aroused, and to experience distress and agitation when subjected to stress. In scope of our results, $\mathrm{N}$ trait's moderating influence on the connection between age and cognitive processing may be explained in the context of the results of a recent study on neuroticism's regulatory role in behavior, which indicates that the level of $\mathrm{N}$ trait is strongly related to anxiety, rather than impulsivity [46]. This theory is confirmed by the fact that the situation of an experiment can be referred to as a source of stress, and how well the subjects cope with performing the assigned task depends on the level of anxiety. In such situations of emotional stress, the conditions of the task activate the limbic system, which allows the connection between neuroticism and stimulation to appear [46]. While in younger persons anxiety may play a mobilizing role, in older people it had a disorganizing influence [45]. This interpretation means that the level of personality traits changes its functional meaning as one ages, even though the combination of these personality traits may stay constant. It is quite likely that this change occurs concurrently with the changes in the nervous system, which would explain the additive influence of the $\mathrm{N}$ and age variables. In his study of memory functioning in older people, Wilson et al. [26] demonstrated a very strong correlation between a decline in the memory functioning and the level of $\mathrm{N}$ trait. Additionally, the likelihood of clinical symptoms of Alzheimer's disease occurrence was twice as high in persons who scored highly on the $\mathrm{N}$ measure in comparison to persons with lower scores. This result is explained by the fact that prolonged stress (as indexed by high levels of neuroticism) may take part in neurophysiological functions deterioration, which is reflected in the decreased memory functioning [26]. Many highly reliable studies indicate the existence of the influence of age and the $\mathrm{N}$ and $\mathrm{E}$ trait levels on neurotransmitters functioning $[46,47]$. It is possible to hypothesize that our results can be explained by the fact that the interaction between age and personality traits observed in our study was the effect of the correlation of these variables with biochemical factors. For instance, the results of the research conducted by Kaasinen et al. [48] on the age-related dopamine D2/D3 receptor loss in extrastriatal regions of the human brain support such hypothesis [49].

Obviously, such interpretation in this early phase of the research is rather a speculation and requires further 
verification on the biochemical study level. We are not aware of existing research results which would refer to changes in cognitive processing depending on the personality traits level and biochemical factors concurrently.

Finally, we reach the question of the scope of conclusions derived from our research as applied to examining drivers. Proving that age influences the level of basic cognitive functions and that, in the case of most cognitive processes, this influence is stronger, correspondingly to higher neuroticism level, is not conclusive enough to directly assume that older people characterized by high level of neuroticism will make more errors in traffic or will cause more accidents. Nevertheless, these results may suggest that cooccurrence of both of these factors creates conditions in which the risk is higher, which has been previously proven by studies indicating a connection between anxiety and accident proneness [50]. These matters require further research, however, our study strongly suggests that the level of $\mathrm{N}$ trait may play an important role in the process of cognitive aging.

\section{REFERENCES}

1. Sommer M, Herle M, Häusler J, Risser R, Schützhofer B, Chaloupka Ch. Cognitive and personality determinants of fitness to drive. Transport Res F Traffic Psychol Behav 2008;11:362-75.

2. Uhlenberg P. International handbook of population aging. Dordrecht: Springer; 2009.

3. Marottoli RA, Mendes de Leon CF, Glass TA, Williams CS, Cooney LM, Berkman LF. Consequences of Driving Cessation: Decreased Out-of-Home Activity Levels. J Gerontol B Psychol 2000;55:334-40.

4. Ragland DR, Satariano WA, MacLeod KE. Driving Cessation and Increased Depressive Symptoms. J Gerontol A Biol Sci 2005;60:399-403.

5. Ball K, Owsley C, Sloane ME, Roenker DL, Bruni JR. Visual attention problems as a predictor of vehicle crashes in older drivers. Invest Ophthalmol Vis Sci 1993;34:3110-23.
6. Owsley C, Ball K, McGwin G, Sloane M, Roenker D, White M, et al. Visual processing impairment and risk of motor vehicle crash among older adults. J Am Med Assoc 1998;279:1083-8.

7. Kline DW, Kline TJB, Fozard JL, Kosnik W, Schieber F, Sekuler R. Vision, aging and driving: The problems of older drivers. J Gerontol B Psychol 1992;47:27-34.

8. McKnight AJ, McKnight AS. Multivariate analysis of agerelated driver ability and performances deficits. Accid Anal Prev 1999;31:445-54.

9. Williams AF. Magnitude and characteristics of the young driver crash problem in the United States. In: Simpson H, editor. New to the Road: Reducing the Risks for Young Motorists. Los Angeles: UCLA School of Medicine; 1996. p. 19-25.

10. Ryan GA, Legge M, Rosman D. Age related changes in drivers' crash risk and crash type. Accid Anal Prev 1998;30: 379-87.

11. Evans L. Traffic Safety. Bloomfield Hills, MI: Science Serving Society; 2004.

12. Porter M, Whitton J. Assessment of driving with the global positioning system and video technology in young, middle-aged and older drivers. J Gerontol A Med Sci 2002;57:578-82.

13. Wood JM. Age and visual impairment decrease driving performance as measured on a closed-road circuit. Hum Factors 2002;44:482-94.

14. Birren JE, Fisher LM. Aging and speed of behavior: Possible consequences for psychological functioning. Annu Rev Psychol 1995;46:329-53.

15. Rabbitt P. Speed of processing and ageing. In: Woods $R$, editor. Handbook of clinical psychology of Ageing. Chichester: Wiley; 1996. p. 59-72.

16. Salthouse TA. Aging and measures of processing speed. Biol Psychol 2000;54:35-54.

17. Hartley A. Changing Role of the Speed of Processing Construct in the Cognitive Psychology of Human Aging. In: Birren JE, Schaie KW, editors. Handbook of The Psychology of Aging. 6th ed. San Diego, CA: Elsevier; 2006. p. 183-207.

18. Guan J, Wade MG. The effect of aging on adaptive eye-hand coordination. J Gerontol B Psychol 2000;55:151-62. 
19. Scialfa CT, Guzy LT, Leibowitz HW, Garvey PM, Tyrrell RA. Age differences in estimating vehicle velocity. Psychol Aging 1991;6:60-6.

20. Gilmore GC, Wenk HE, Naylor LA, Stuve TA. Motion perception and aging. Psychol Aging 1992;7:654-60.

21. Staplin L, Lococo K, Sim J. Traffic maneuver problems of older drivers. Report No. FHWA-RD-92-092. McLean, VA: Federal Highway Administration; 1993.

22. Zuckerman M. Biological bases of personality. In: Millon T, Lerner MJ, editors. Handbook of psychology: Vol. 5. Personality and social psychology. New York: Wiley; 2003. p. 85-116.

23. Eysenck SBG, Eysenck HJ, Barrett P. A revised version of the Psychoticism scale. Pers Indiv Differ 1985;6:21-9.

24. Renner W, Anderle F. Venturesomeness and extraversion as correlates of juvenile drivers' traffic violations. Accid Anal Prev 2000;32:673-8.

25. Lajunen T. Personality and accident liability: are extroversion, neuroticism and psychoticism related to traffic and occupational fatalities? Pers Indiv Differ 2001;31:1365-73.

26. Wilson T, Greensmith J. Multivariate analysis of the relationship between drivometer variables and drivers' accident, sex, and exposure status. Hum Factors 1983;25:303-12.

27. Pestonjee DM. Singh UB. Neuroticism-extroversion as correlates of accident occurrence. Accid Anal Prev 1980;12:201-4.

28. Clarke S, Robertson I. An Examination of the Role of Personality in Work Accidents Using Meta-analysis. Appl Psychol-Int Rev 2008;57:94-108.

29. Smith DI, Kirkham RW. Relationship between some personality characteristics and driving record. Br J Soc Psychol 1981;20:229-31.

30. Wilson RS, Bennett DA, Bienias JL, Aggarwal NT, Mendes de Leon CF, Morris MC, et al. Cognitive activity and incident $A D$ in a population-based sample of older persons. Neurology 2002;59:1910-4.

31. Matthews G, Dorn L, Glendon AI. Personality correlates of driver stress. Pers Indiv Differ 1991;12:535-49.

32. Dorn L, Matthews G. Two further studies of personality correlates of driver stress. Pers Indiv Differ 1992;13:949-51.
33. Brzozowski P, Drwal RL. Manual of the Eysenck Personality Questionnaire EPQ-R. Warszawa: PTP; 1995 [in Polish].

34. Risser R, Chaloupka Ch, Grundler W, Sommer M, Häusler J, Kaufmann C. Using non-linear methods to investigate the criterion validity of traffic-psychological test batteries. Accid Anal Prev 2008;40:149-57.

35. Miller JO, Low K. Motor processes in simple, go/no-go, and choice reaction time tasks: a psychophysiological analysis. J Exp Psychol Hum Percept Perform 2001;27:266-89.

36. Schuhfried G. Manual Reaction Test (RT). Modling: Schuhfried $\mathrm{GmbH} ; 1997$.

37. Schuhfried G. Peripheral Perception Test (PP). Modling: Schuhfried GmbH; 2005.

38. Jaworowska A, Szustrowa T. Manual for Raven's Progressive Matrices. Warszawa: PTP; 2000 [in Polish].

39. Jensen AR. Reaction time and psychometric g. In: Eysenck HJ, editor. A model for intelligence. Heidelberg: Springer-Verlag; 1982. p. 93-102.

40. Dawson JF, Richter AW. Probing Three-Way Interactions in Moderated Multiple Regression: Development and Application of a Slope Difference Test. J Appl Psychol 2006;91:917-26.

41. Aiken LS, West SG. Multiple regression: Testing and interpreting interactions. Newbury Park: Sage; 1991.

42. Schaie KW, Willis SL. Age difference patterns of psychometric intelligence in adulthood: Generalizability within and across ability domains. Psychol Aging 1993;8:44-55.

43. Hertzog C, Bleckley MK. Age differences in the structure of intelligence: Influences of information processing speed. Intelligence 2001;29:191-217.

44. Wetherell JL, Reynolds CA, Gatz M, Pedersen NL. Anxiety, Cognitive Performance, and Cognitive Decline in Normal Aging. J Gerontol B Psychol 2002;57:246-55.

45. Robinson MD, Tamir M. Neuroticism as mental noise: a relation between neuroticism and reaction time standard deviations. J Pers Soc Psychol 2005;89:107-14.

46. Gray JA, McNaughton N. The neuropsychology of anxiety: an enquiry into the functions of the septo-hippocampal system. 2nd ed. Oxford: Oxford University Press; 2000. 
47. Backman L, Farde L. The role of dopamine systems in cognitive aging. In: Cabeza R, Nyberg L. Park D, editors. Cognitive neuroscience of aging. New York: Oxford University Press; 2005. p. 58-84.

48. Kaasinen V, Vilkman H, Hietala J, Nagren K, Helenius H, Olsson $\mathrm{H}$, et al. Age-related dopamine D2/D3 receptor loss in extrastriatal regions of the human brain. Neurobiol Aging 2000;21:683-8.
49. Erixon-Lindroth N, Farde L, Whalin TB, Sovago J, Halldin $\mathrm{C}$, Backman L. The role of the striatal dopamine transporter in cognitive aging. Psychiat Res-Neuroim 2005;138:1-12.

50. Simon F, Corbett C. Road traffic offending, stress, age, and accident history among male and female drivers. Ergonomics 1996;39:757-80.

This work is available in Open Access model and licensed under a Creative Commons Attribution-NonCommercial 3.0 Poland License - http://creativecommons.org/ licenses/by-nc/3.0/pl/deed.en. 